\title{
Growth, spectroscopy, and tunable laser operation of the disordered crystal $\mathrm{LiGd}\left(\mathrm{MoO}_{4}\right)_{2}$ doped with ytterbium
}

\author{
20 \\ M. Rico, U. Griebner, and V. Petrov \\ Max-Born-Institute for Nonlinear Optics and Ultrafast Spectroscopy, 2 A Max-Born-Street, \\ D-12489 Berlin, Germany \\ P. Ortega \\ Instituto de Cerámica y Vidrio, Consejo Superior de Investigaciones Científicas, c/ Kelsen 5, Cantoblanco, \\ Madrid, Spain
}

H. Xiumei, C. Cascales, and C. Zaldo

Instituto de Ciencia de Materiales de Madrid, Consejo Superior de Investigaciones Científicas, c/ Sor Juana Inés de la Cruz 3, Cantoblanco, E-28049 Madrid, Spain

Received July 11, 2005; revised January 9, 2006; accepted January 24, 2006; posted February 3, 2006 (Doc. ID 63249)

\begin{abstract}
The disordered crystal $\mathrm{LiGd}_{0.936} \mathrm{Yb}_{0.064}\left(\mathrm{MoO}_{4}\right)_{2}$ was grown with high optical quality by the flux method using $\mathrm{Li}_{2} \mathrm{MoO}_{4}$ as a solvent. The crystal possesses tetragonal symmetry belonging to the space group $I \overline{4}$, with two nonequivalent sites occupied by the dopant. Spectroscopic studies at 5 and $300 \mathrm{~K}$ provided information on the Stark energy-level splitting and the absorption and emission cross sections of the $\mathrm{Yb}^{3+}$ ion. Laser operation of $\mathrm{Yb}^{3+}$ was obtained for the first time in such a Li-containing double tungstate or molybdate. The tuning range with a Ti:sapphire laser pumping extended over $\sim 32 \mathrm{~nm}$ for the $\sigma$ polarization and $23 \mathrm{~nm}$ for the $\pi$ polarization. Without a tuning element the laser performance was similar for the two polarizations. By using a $10 \%$ transmission output coupler, a maximum output power of $\approx 470 \mathrm{~mW}$ was obtained with a slope efficiency $\eta$ $=64.5 \%$ and the absorbed pump power at threshold was $520 \mathrm{~mW}$. Laser operation was also achieved by pumping with a tapered diode laser and a fiber-coupled diode laser module, with a $\mathrm{Yb}$ laser output power of $0.66 \mathrm{~W}$ in the latter case. (C) 2006 Optical Society of America
\end{abstract}

OCIS codes: $140.3380,140.5680,140.3480,140.3070,140.3580,140.3600$.

\section{INTRODUCTION}

Several sodium double tungstate (DT) and double molybdate (DM) single crystals with tetragonal structure and formula $\mathrm{NaT}\left(\mathrm{XO}_{4}\right)_{2}$ (T: trivalent ion, e.g., lanthanide, and $\mathrm{X}=\mathrm{W}$ or Mo) were studied recently as laser hosts for tunable $\mathrm{Yb}^{3+}$ emission in the $1 \mu \mathrm{m}$ spectral range. In particular, laser operation was demonstrated for the first time to our knowledge in $\mathrm{Yb}: \mathrm{NaGd}\left(\mathrm{WO}_{4}\right)_{2}{ }^{1-3} \mathrm{Yb}: \mathrm{NaLa}\left(\mathrm{WO}_{4}\right)_{2},{ }^{4,5}$ and $\mathrm{Yb}: \mathrm{NaLa}\left(\mathrm{MoO}_{4}\right)_{2} \cdot{ }^{4,6,7}$ These lasers could be tuned in a relatively broad spectral region, e.g., up to $48 \mathrm{~nm}$ around $1040 \mathrm{~nm}$ for $\mathrm{Yb}: \mathrm{NaLa}\left(\mathrm{MoO}_{4}\right)_{2}{ }^{7}$ Such tunability is associated with the strong coupling of the $\mathrm{Yb}^{3+}$ electronic transition to the lattice vibrations and with the increased spectral linewidths of trivalent lanthanides induced by the crystallographic disorder in the $\mathrm{Na}-\mathrm{T}$ cationic sublattice. Further interest arises from the possibility of using this broadband emission to support ultrashort laser-pulse durations near $1 \mu \mathrm{m}$ in the sub-100 fs regime. In fact, the first demonstration of a passively mode-locked $\mathrm{Yb}$ laser based on a disordered sodium DT crystal has already been reported. ${ }^{8}$

Only a limited number of DT and DM compounds can be obtained at room temperature as tetragonal crystals with structural disorder. With few exceptions, most of the $\mathrm{K}, \mathrm{Rb}$, and Cs DT and DM crystals exhibit ordered phases with lower than tetragonal crystalline symmetry at room temperature. For instance, most of the $\mathrm{KT}\left(\mathrm{WO}_{4}\right)_{2}$ compounds have different crystallographic phases at high (close to melting or decomposition) and low (room) temperatures. ${ }^{9}$ In cases when the disordered tetragonal structure exists at high temperature, polymorphic transformation to the low-temperature structure hampers or even prevents the preparation of a stable tetragonal phase with optical quality at room temperature.

Laser operation in general has been demonstrated in the past in only two lithium DT or DM hosts, $\mathrm{LiLa}\left(\mathrm{MoO}_{4}\right)_{2}$ (Refs. 10-12) and $\mathrm{LiGd}\left(\mathrm{MoO}_{4}\right)_{2}$ (Refs. 11, 13, and 14), but in all cases the dopant was $\mathrm{Nd}^{3+}$, which operates as a four-level system. With the title compound $\mathrm{LiGd}\left(\mathrm{MoO}_{4}\right)_{2}$, or LiGdMo for short, the first emission of $\mathrm{Nd}^{3+}$ at $1059.9 \mathrm{~nm}$ for the ${ }^{4} F_{3 / 2} \rightarrow{ }^{4} I_{3 / 2}$ transition was obtained at $300 \mathrm{~K}$ with flash-lamp pumping ${ }^{13}$; soon afterwards a similar setup operated on the ${ }^{4} F_{3 / 2} \rightarrow{ }^{4} I_{3 / 2}$ transition of $\mathrm{Nd}^{3+}$ at $1340 \mathrm{~nm},{ }^{11}$ and finally cw lasing at $1059.9 \mathrm{~nm}$ was obtained in Ref. 14, again with flash-lamp pumping. 
APC: The tetragonal scheelitelike structure was identified \#2 for the whole series of $\mathrm{Li} \mathrm{DM}$ compounds with $\mathrm{T}=\mathrm{La}$ -Lu, Y. ${ }^{15,16}$ Li-based DM compounds melt with decomposition; single crystals of all the DM compounds were obtained using $\mathrm{Li}_{2} \mathrm{MoO}_{4}$ fluxes. ${ }^{15}$ The crystals obtained at high temperature do not exhibit polymorphic transformations upon cooling to room temperature. ${ }^{15}$ On the basis of single-crystal x-ray structural analysis, the centrosymmetric space group $I 4_{1} /$ a was assigned to $\mathrm{LiCe}\left(\mathrm{MoO}_{4}\right)_{2}{ }^{17}$ and also to $\mathrm{LiNd}\left(\mathrm{MoO}_{4}\right)_{2}$ and $\mathrm{LiY}\left(\mathrm{MoO}_{4}\right)_{2} \cdot{ }^{18}$ In the latter work it was suggested that the same symmetry $I 4_{1} / \mathrm{a}$ is characteristic for the whole series $\mathrm{T}=\mathrm{La}-\mathrm{Lu}, \mathrm{Y}$. The only Li-based DM for which a nontetragonal low-temperature phase was identified is $\mathrm{LiLa}\left(\mathrm{MoO}_{4}\right)_{2}$, for which the largest ionic radius difference between the monovalent and trivalent cations occurs. ${ }^{19}$ However, in x-ray diffraction (XRD) analysis the tetragonal space groups $I 4_{1} /$ a (No. 88), $I 4_{1}$ (No. 80), and $I \overline{4}$ (No. 82) are distinguished only on the basis of weak reflections. Therefore a detailed crystallographic study of the Yb-doped LiGdMo crystal, as performed in the present work, was necessary to ascertain the true symmetry.

Recently, an extensive crystal growth and characterization study has been conducted on single crystals of $\mathrm{LiYb}\left(\mathrm{MoO}_{4}\right)_{2} \quad(\mathrm{LiYbMo})$ grown using $\mathrm{Li}_{2} \mathrm{MoO}_{4}$ and $\mathrm{Li}_{2} \mathrm{Mo}_{2} \mathrm{O}_{7}$ solvents. ${ }^{20}$ The high $\mathrm{Yb}$ density in this stoichiometric material $\left(6.87 \times 10^{21} \mathrm{~cm}^{-3}\right)$ results in a large peak optical absorption coefficient $\left(\alpha>125 \mathrm{~cm}^{-1}\right)$ for both polarizations. ${ }^{20}$ Hence, very thin (of the order of $0.2 \mathrm{~mm}$ and less) and difficult to handle active elements will be necessary to control the reabsorption effects in the threelevel operational scheme of the $\mathrm{Yb}^{3+}$ ion. In the present work we investigate the optically inert host LiGdMo and demonstrate for the first time to our knowledge laser operation with such a type of disordered Yb-doped Li DM crystal.

\section{CRYSTAL GROWTH AND STRUCTURAL CHARACTERIZATION}

APC: $\operatorname{LiGd}_{1-x} \mathrm{Yb}_{x}$ Mo crystals were grown in air using a plati\#4 num crucible and a resistance vertical tubular furnace by the top-seeded solution growth technique. The starting chemical products used were antireflection-grade $\mathrm{Li}_{2} \mathrm{CO}_{3}$, $\mathrm{MoO}_{3}, \mathrm{Yb}_{2} \mathrm{O}_{3}$, and $\mathrm{Gd}_{2} \mathrm{O}_{3}$ and the solvent was $\mathrm{Li}_{2} \mathrm{MoO}_{4}$. The growth mixture consisted of $50 \mathrm{~mol} . \% \mathrm{Li}_{2} \mathrm{MoO}_{4}$ and 50 mol.\% $\mathrm{LiGd}_{0.9} \mathrm{Yb}_{0.1} \mathrm{Mo}$. The crucible filled with the charge was heated in the furnace to $1030^{\circ} \mathrm{C}$, i.e., $50^{\circ} \mathrm{C}$ above the observed charge melting. The liquid was kept at this constant temperature for four days to achieve a homogeneous melt. Some melt evaporation was evident from the nucleation of needle-shaped microcrystals around the pulling wire. The resolidified phase was identified as $\mathrm{Li}_{0.04} \mathrm{MoO}_{3}{ }^{21}$ The saturation temperature of the solution was determined by repeated seeding. During the growth process, the crystal was slowly cooled at a rate of $1^{\circ} \mathrm{C} /$ day and rotated at a rate of $4.5 \mathrm{rpm}$. Finally, the crystal was pulled out from the melt and cooled down to room temperature at a rate of $15^{\circ} \mathrm{C} / \mathrm{h}$. Figure 1 shows a polished crystal plate used in the present laser study.

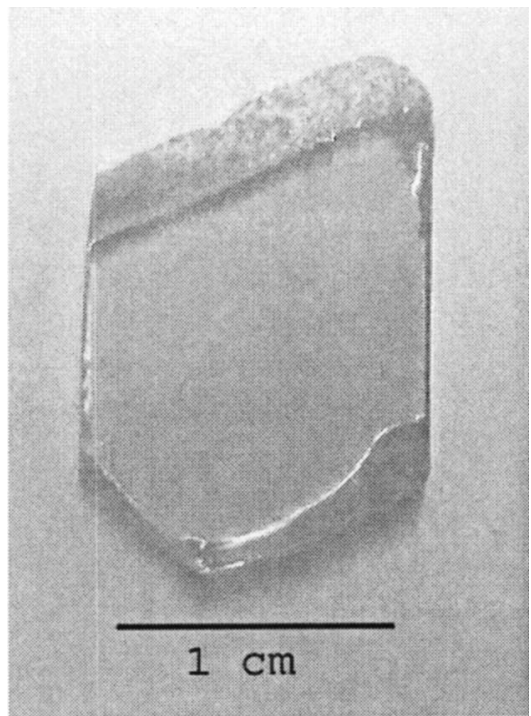

Fig. 1. Polished $\mathrm{LiGd}_{0.936} \mathrm{Yb}_{0.064}\left(\mathrm{MoO}_{4}\right)_{2}$ plate used in the laser experiments.

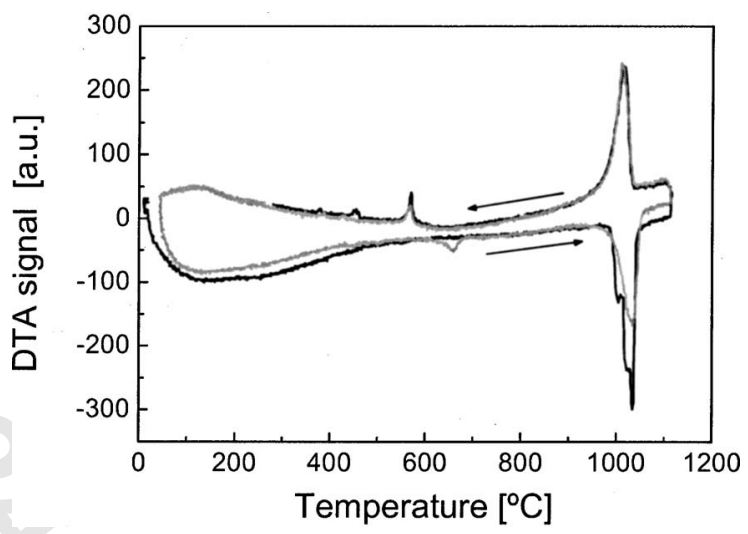

Fig. 2. Differential thermal analysis (DTA) of the $\mathrm{LiGd}_{0.936} \mathrm{Yb}_{0.064}\left(\mathrm{MoO}_{4}\right)_{2}$ crystal. The first cycle is shown by the black curve, and the second cycle is shown by the gray curve. The decomposition melting character is evident from the complex nature of the endothermic peak at $1000^{\circ} \mathrm{C}$, its change between the first and second cycles, and by the appearance of new peaks after the first cycle melting.

Simultaneous thermogravimetric and differential thermal analysis (DTA) were performed in air using $\mathrm{Al}_{2} \mathrm{O}_{3}$ as a reference. Heating and cooling ramps were at a $10^{\circ} \mathrm{C} / \mathrm{min}$ rate. To assess the melting character, the samples were subjected to two consecutive melting and resolidification cycles. The DTA results revealed that the doped crystal melts with decomposition. This is evident from Fig. 2 by the presence of several overlapping peaks constituting the endothermic feature starting at $\sim 1000^{\circ} \mathrm{C}$. The comparison with the stoichiometric LiYbMo crystal ${ }^{20}$ shows that the increase of the $\mathrm{Yb}$ concentration reduces the melting and decomposition temperature, in agreement with previous observations for the $\mathrm{LiT}\left(\mathrm{MoO}_{4}\right)_{2}$ series in the region $\mathrm{T}=\mathrm{Gd}$ Lu. $^{15}$

The $\mathrm{Yb}$ concentration in the grown $\mathrm{Yb}$ :LiGdMo boule was estimated by inductively coupled plasma emission using an axial plasma spectrometer. It was $6.4 \mathrm{~mol} . \%$ leading to an actual crystal composition of $\mathrm{LiGd}_{0.936} \mathrm{Yb}_{0.064} \mathrm{Mo}$. This value along with the cell volume 
obtained from the lattice parameters gives a $\mathrm{Yb}$ density of $4.06 \times 10^{20} \mathrm{~cm}^{-3}$ in the grown boule.

$\mathrm{XRD}$ analysis of $\mathrm{Yb}$ :LiGdMo was performed with a selected prismatic-cut single crystal from the grown material, using the equipment and methods previously described. ${ }^{20}$ Details for the data collection and refinement of the structure are summarized in Table 1.

Initially the structure of the Yb-doped LiGdMo crystal was refined for coordination of the atoms in the space group $I 4_{1}$ /a that gave a discrepancy factor $R_{1}=0.0708$. The $(\mathrm{Gd}+\mathrm{Yb})$ and $\mathrm{Li}$ atoms in this unit cell randomly occupy the same $4 b$ site with an occupancy factor of 0.5 . However, several weak Bragg reflections $\left(\begin{array}{lll}0 & 0 & l\end{array}\right), l$ is even but $l \neq 4 n$ and ( $h-h 0), h \neq 2 n$, which are forbidden for the space group $I 4_{1} / \mathrm{a}$, were present in the collected data. Seven of them, with an intensity higher than $3 \sigma(F)$, constitute violations of the $a$ plane but they are allowed for both $I 4_{1}$ and $I \overline{4}$ space groups. However, the other two reflections, also with $I>3 \sigma(F)$, are forbidden for the $4_{1}$ axis, which leads to the space group $I \overline{4}$. Moreover, the discrep-

Table 1. Crystal Data at 296 (2) $\mathrm{K}$ and Structure Refinement for $\mathrm{Yb}: \mathrm{LiGd}\left(\mathrm{MoO}_{4}\right)_{2}$

\begin{tabular}{|c|c|}
\hline Wavelength $(\AA)$ & 0.71073 \\
\hline $\begin{array}{l}\text { Crystal system, } \\
\text { space group }\end{array}$ & Tetragonal, $I \overline{4}$ \\
\hline \multirow[t]{2}{*}{$\begin{array}{l}\text { Unit cell dimensions } \\
(\AA)\end{array}$} & $a=b=5.1814(10)$ \\
\hline & $c=11.285(3)$ \\
\hline Volume $\left(\AA^{3}\right)$ & $302.98(11)$ \\
\hline$Z$, calculated density $\left(\mathrm{Mg} / \mathrm{m}^{3}\right)$ & $2,5.306$ \\
\hline Absorption coefficient $\left(\mathrm{mm}^{-1}\right)$ & 14.894 \\
\hline$F(000)$ & 430 \\
\hline Crystal size (mm) & $0.20 \times 0.20 \times 0.10$ \\
\hline $\begin{array}{l}\theta \text { range for data } \\
\text { collection (deg) }\end{array}$ & 4.33-28.85 \\
\hline Limiting indices & $\begin{array}{c}-6 \leqslant h \leqslant 2,-6 \leqslant k \leqslant 6 \\
-12 \leqslant l \leqslant 13\end{array}$ \\
\hline $\begin{array}{l}\text { Reflections collected/ } \\
\text { independent (unique) }\end{array}$ & $686 / 296[R(\mathrm{int})=0.0263]$ \\
\hline Absorption correction & SADABS \\
\hline Refinement method & $\begin{array}{c}\text { Full matrix } \\
\text { least squares on } F^{2}\end{array}$ \\
\hline Data, restraints, parameters & $296,2,34$ \\
\hline Goodness of fit on $F^{2}$ & 1.119 \\
\hline Final $R$ indices $[I>2 \sigma(I)]$ & $R_{1}=0.0583, w R_{2}=0.1998$ \\
\hline$R$ indices (all data) & $R_{1}=0.0605, w R_{2}=0.2060$ \\
\hline Extinction coefficient & $0.1009(9)$ \\
\hline & $\begin{array}{l}\text { Site, atomic coordinates } \\
\qquad\left(\times 10^{4}\right), U_{(\mathrm{eq})}{ }^{a}:\end{array}$ \\
\hline $\mathrm{Gd}(1) / \mathrm{Yb}(1) / \mathrm{Li}(1)$ & $2 d 500002500,9(2)$ \\
\hline $\mathrm{Gd}(2) / \mathrm{Yb}(2) / \mathrm{Li}(2)$ & $2 b 500050000,7(1)$ \\
\hline $\mathrm{Mo}(1)$ & $2 a 000,9(1)$ \\
\hline $\mathrm{Mo}(2)$ & $2 c 050002500,9(1)$ \\
\hline $\mathrm{O}(1)$ & $\begin{array}{c}8 f 2425(16) 1540(20) \\
857(10), 12(2)\end{array}$ \\
\hline $\mathrm{O}(2)$ & $\begin{array}{c}8 f \text { 2401(18) } 3490(20) \\
1657(14), 25(3)\end{array}$ \\
\hline
\end{tabular}

${ }^{a}$ Equivalent isotropic displacement parameters $U_{(\mathrm{eq})}\left(\AA^{2} \times 10^{3}\right)$ defined as one third of the trace of the orthogonalized $U_{i j}$ tensor. The crystallographic refinement also included all positive anisotropic displacement, parameters, not given in the table for the sake of simplicity. ancy factor when the crystal was refined in the space group $I \overline{4}$ decreased to $R_{1}=0.0583$, with satisfactory positive anisotropic displacement parameters for all atoms of the current Yb-doped LiGdMo crystal. Finally, we note that the noncentrosymmetric space group $I \overline{4}$ coincides with the one determined for LiYbMo (Ref. 20) and that the lattice parameters of $\mathrm{LiGd}_{0.936} \mathrm{Yb}_{0.064} \mathrm{Mo}$ lie between those of LiGdMo and LiYbMo. ${ }^{15,20,22}$

The above structural determination is important for the understanding of the optical properties of such disordered crystals, since the space group $I \overline{4}$ has two nonequivalent $2 b$ and $2 d$ sites with $S_{4}$ point symmetry occupied by $\mathrm{Li}^{+}, \mathrm{Gd}^{3+}$, or $\mathrm{Yb}^{3+}$ (see Table 1 ) with specific occupancy factors. From the macroscopic point of view provided by the XRD analysis, these sites are characterized by different cation-oxygen distances, namely, for the site $\quad 2 d \mathrm{Gd}(1) / \mathrm{Li}(1) / \mathrm{Yb}(1)-\mathrm{O}(1)=2.419(11) \AA \quad$ and $\mathrm{Gd}(1) / \mathrm{Li}(1) / \mathrm{Yb}(1)-\mathrm{O}(2)=2.448(13) \AA$, and for the site $2 b \mathrm{Gd}(2) / \mathrm{Li}(2) / \mathrm{Yb}(2)-\mathrm{O}(1)=2.437(11) \AA, \quad$ and $\mathrm{Gd}(2) / \mathrm{Li}(2) / \mathrm{Yb}(2)-\mathrm{O}(2)=2.433(13) \AA$. Moreover, the occupancy factors obtained without imposing charge restraints between both sites are $(\mathrm{Gd}+\mathrm{Yb}) / \mathrm{Li}[0.50(4) /$ $0.49(1)$ in $2 b]$ and $(\mathrm{Gd}+\mathrm{Yb}) / \mathrm{Li}[0.51(4) / 0.49(1)$ in $2 d]$. Since these occupancy factors are very close to the statistical distribution over both sites, a high degree of disorder is assigned to the current crystal. This will give rise to a further contribution to the inhomogeneous broadening of the $\mathrm{Yb}^{3+}$ optical properties in comparison to the space group $I 4_{1} /$ a assumption where a single $4 b$ site for the $\mathrm{Li}^{+}$, $\mathrm{Gd}^{3+}$, or $\mathrm{Yb}^{3+}$ cations exists.

\section{ABSORPTION AND EMISSION CROSS SECTIONS}

Single-crystal $\mathrm{LiGd}_{0.936} \mathrm{Yb}_{0.064} \mathrm{Mo}$ samples oriented by the Laue technique were used in the optical studies. Polarized spectra are labeled as $\pi(\boldsymbol{E} \mid / \boldsymbol{c})$ and $\sigma(\boldsymbol{H} \mid / \boldsymbol{c})$. This crystal is transparent in the UV down to $\sim 350 \mathrm{~nm}$ at $300 \mathrm{~K}$. At this temperature, the difference in the UV absorption edge for $\sigma$ - and $\pi$-polarized light was very small, $<0.5 \mathrm{~nm}$. At $5 \mathrm{~K}$ the UV absorption edge moved to $\sim 340 \mathrm{~nm} \quad(\sim 1 \mathrm{~nm}$ shorter for $\pi$-polarized than for $\sigma$-polarized light).

To evaluate the crystal field splitting of the ground, ${ }^{2} F_{7 / 2}$, and excited, ${ }^{2} F_{5 / 2}$, multiplets of $\mathrm{Yb}^{3+}$, we measured the absorption and emission spectra at a low temperature $(5 \mathrm{~K})$. Figure $3(\mathrm{a})$ shows the polarized absorption and Fig. 3 (b) the unpolarized and $\pi$-polarized photoluminescence. The common absorption and photoluminescence band at $10,263 \mathrm{~cm}^{-1}$ indicates the energy position $\left(E_{z l}\right)$ of the ${ }^{2} F_{7 / 2}(0) \leftrightarrow{ }^{2} F_{5 / 2}\left(0^{\prime}\right)$ zero-phonon transition. Within our experimental uncertainty $(0.2 \mathrm{~nm})$ the position of this band in the $5 \mathrm{~K}$ photoluminescence was independent of the excitation wavelength, which means that the contribution of the coexisting $\mathrm{Yb}^{3+}$ centers cannot be resolved.

The other well-resolved bands in the $5 \mathrm{~K}$ absorption spectrum [Fig. 3(a)] are related to the energy position of the ${ }^{2} F_{5 / 2}\left(n^{\prime}\right)$ levels. It is tempting to ascribe the spectral structure observed at 10,647 and $10,708 \mathrm{~cm}^{-1}$ to separate contributions of $\mathrm{Yb}^{3+}$ ions in the aforementioned $2 b$ and $2 d$ crystal sites. This possibility was checked by applying 

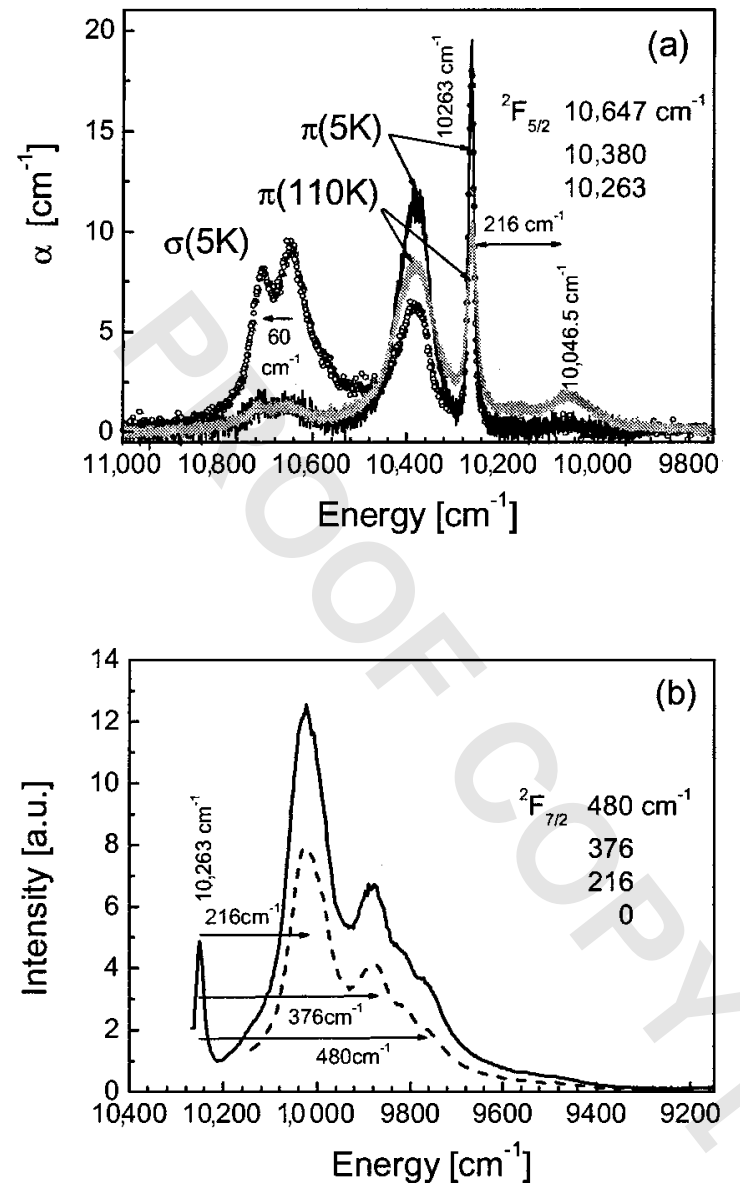

Fig. 3. Low-temperature spectroscopy of $\mathrm{Yb}^{3+}$ in LiGdMo. (a) Polarized absorption spectra recorded at 5 and $110 \mathrm{~K}$. (b) $5 \mathrm{~K}$ photoluminescence after excitation at $973 \mathrm{~nm}\left(10,278 \mathrm{~cm}^{-1}\right)$ to the ${ }^{2} F_{5 / 2}\left(0^{\prime}\right)$ level (dashed curve $\pi$-polarized record) and after excitation at $960 \mathrm{~nm}\left(10,417 \mathrm{~cm}^{-1}\right)$ to the ${ }^{2} F_{5 / 2}\left(1^{\prime}\right)$ level (solid curve, unpolarized record).

the semiempirical simple overlap model (SOM) $)^{23}$ that allows us to estimate the crystal field parameters (CFPs) from the crystallographic positions of the $\mathrm{Gd}($ or $\mathrm{Yb}) \mathrm{O}_{8}$ coordination polyhedra. Separate sets of CFPs for the $\mathrm{Yb}$ ions in the $2 b$ and $2 d$ sites were obtained from the atomic coordinates given in Table 1 and the corresponding $\mathrm{Yb}-\mathrm{O}$ distances. In both cases the obtained values of the six CFPs corresponding to the $S_{4}$ symmetry were introduced in the simulation of the ${ }^{2} F_{7 / 2}(n)$ and ${ }^{2} F_{5 / 2}\left(n^{\prime}\right)$ Stark energy-level energies for the $4 f$ (Ref. 13) configuration, along with free-ion (FI) parameters previously determined for the isostructural $\mathrm{NaBi}\left(\mathrm{WO}_{4}\right)_{2}$ host. ${ }^{24}$ The simulation was performed using a previously developed code. ${ }^{25}$ The used FI parameters, the derived SOM CFPs, and the corresponding energy-level schemes obtained for $\mathrm{Yb}^{3+}$ in each site are summarized in Table 2 . The energy difference between both sites for the ${ }^{2} F_{7 / 2}(0) \rightarrow{ }^{2} F_{5 / 2}\left(2^{\prime}\right)$ transition obtained from this simulation was $\sim 3 \mathrm{~cm}^{-1}$. This is much less than the energy separation of the two bands at 10,647 and $10,708 \mathrm{~cm}^{-1}$ in Fig. 3(a) and it can be concluded that they are not due to $\mathrm{Yb}^{3+}$ in different crystal sites. In view of the agreement between the observed energy position of the band at $10,263 \mathrm{~cm}^{-1}$ in Fig. 3(a) with the energy-level calculations for the ${ }^{2} F_{7 / 2}(0) \rightarrow{ }^{2} F_{5 / 2}\left(0^{\prime}\right)$ transition that confirms the reliability of the method used, we ascribe the band at $10,647 \mathrm{~cm}^{-1}$ to the ${ }^{2} F_{7 / 2}(0)$ $\rightarrow{ }^{2} F_{5 / 2}\left(2^{\prime}\right)$ transition involving unresolved contributions from both sites and the secondary band observed at $10,708 \mathrm{~cm}^{-1}$ likely to coupling with a phonon of energy roughly equal to $60 \mathrm{~cm}^{-1}$.

The energy position of the first excited ${ }^{2} F_{7 / 2}(1)$ Stark level was determined from the absorption spectrum recorded at $110 \mathrm{~K}$ [see Fig. 3(a)]. The $5 \mathrm{~K}$ photoluminescence spectrum shown in Fig. 3(b) also exhibits wellresolved bands with an associated structure related to the simultaneous deexcitation of the ${ }^{2} F_{5 / 2}\left(0^{\prime}\right)$ and ${ }^{2} F_{5 / 2}\left(1^{\prime}\right)$ levels. The weak band observed at $\sim 9810 \mathrm{~cm}^{-1}$ is also likely due to a $60 \mathrm{~cm}^{-1}$ phonon coupling of the sidebands. The analysis of these spectra allowed the assignment of the energy levels indicated in Figs. 3(a) and 3(b). These energy levels must be understood as the average energy positions of the $\mathrm{Yb}^{3+}$ centers induced by the nonequivalent $2 b$ and $2 d$ lattice sites and their multiple environments due to the random distribution of $\mathrm{Li}^{+}, \mathrm{Gd}^{3+}$, and $\mathrm{Yb}^{3+}$ cations over the same $2 b$ and $2 d$ lattice sites.

The room-temperature $\mathrm{Yb}^{3+}$ absorption cross sections are shown in Fig. 4. The $\mathrm{Yb}^{3+}$ emission cross sections can be calculated by the reciprocity method ${ }^{26}$ using the relationship $\sigma_{e}(h \nu)=\left(Z_{l} / Z_{u}\right) \sigma_{a}(h \nu) \times \exp \left[\left(E_{z l}-h \nu\right) / k_{B} T\right]$ where $Z_{l}$ and $Z_{u}$ are the partition functions of the lower and upper multiplets and $Z=\Sigma_{i} d_{i} \exp \left(-E_{i} / k_{B} T\right)$ with $d_{i}$ denoting the level degeneracy. With the determined energy positions $\left(E_{i}\right)$ of the $\mathrm{Yb}^{3+}$ levels in the ground and excited multiplets, we arrived at $Z_{l} / Z_{u}=0.937$. Figure 4 shows the calculated emission cross sections and their comparison with the $300 \mathrm{~K}$ photoluminescence. It is obvious that reabsorption affects the measured photoluminescence signal at short wavelengths.

The other (alternative) method for calculation of the emission cross sections, the Fürchtbauer-Ladenburg equation, is not applicable in the case of the three-level

Table 2. FI ( $E^{0}$ and $\left.\zeta\right)$ Parameters and Calculated SOM CFPs $\left(B_{0}^{2}, B_{0}^{4}, B_{4}^{4}, B_{0}^{6}, B_{4}^{6}\right.$, and $\left.S_{4}^{6}\right)$ Used to Determine the ${ }^{2} F_{7 / 2}(n)$ and ${ }^{2} F_{5 / 2}\left(n^{\prime}\right)$ Energy Levels of $\mathrm{Yb}^{3+}$ in the $2 b$ and $2 d$ Sites of LiGdMo ${ }^{a}$

\begin{tabular}{|c|c|c|}
\hline Site & $2 b$ & $2 d$ \\
\hline$E^{0}$ & & \\
\hline$\zeta$ & & \\
\hline$B_{0}^{2}$ & 486 & 516 \\
\hline$B_{0}^{4}$ & -612 & -600 \\
\hline$B_{4}^{4}$ & \pm 652 & \pm 630 \\
\hline$B_{0}^{6}$ & -51 & -97 \\
\hline$B_{4}^{6}$ & \pm 531 & \pm 522 \\
\hline$S_{4}^{6}$ & \pm 123 & \pm 105 \\
\hline${ }^{2} F_{5 / 2}\left(2^{\prime}\right)$ & 10,623 & 10,628 \\
\hline${ }^{2} F_{5 / 2}\left(1^{\prime}\right)$ & 10,361 & 10,353 \\
\hline${ }^{2} F_{5 / 2}\left(0^{\prime}\right)$ & 10,263 & 10,266 \\
\hline${ }^{2} F_{7 / 2}(3)$ & 475 & 483 \\
\hline${ }^{2} F_{7 / 2}(2)$ & 328 & 322 \\
\hline${ }^{2} F_{7 / 2}(1)$ & 211 & 206 \\
\hline${ }^{2} F_{7 / 2}(0)$ & 0 & 3 \\
\hline
\end{tabular}

${ }^{a}$ Parameters and energies are given in $\mathrm{cm}^{-1}$. Overlap between $\mathrm{Yb}$-ligand (oxygen) orbital wave functions: $\rho=0.067$; effective charge for oxygen, -0.8 . 


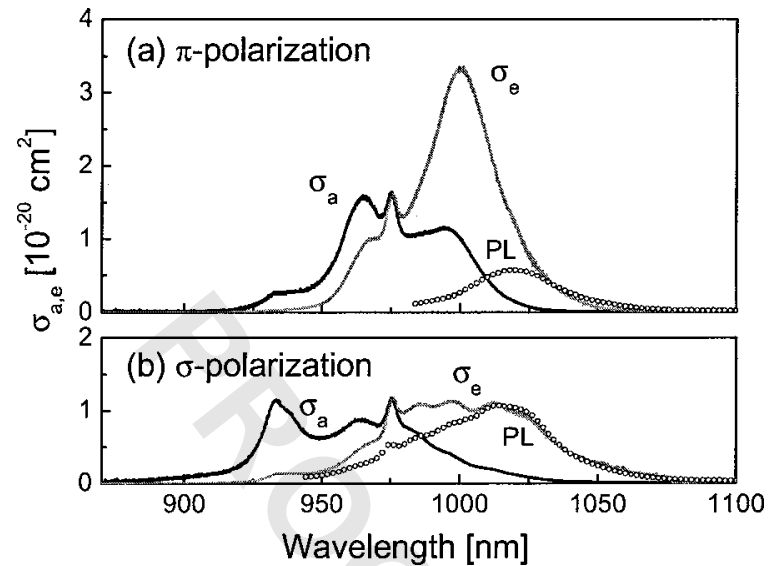

Fig. 4. Room-temperature absorption cross sections ( $\sigma_{a}$, black curves) and comparison between the calculated emission cross sections ( $\sigma_{e}$, gray curves) and the $300 \mathrm{~K}$ photoluminescence (PL, circles).

$\mathrm{Yb}$ system because of the above-mentioned reabsorption. However, by requiring that the results obtained by the two methods are identical, one can estimate the radiative lifetime. This is equivalent to calculating it from $\left(1 / \tau_{\mathrm{rad}}\right)$ $=8 \pi n^{2} \int\left[\left\langle\sigma_{e}(\nu)\right\rangle / \lambda^{2}\right] \mathrm{d} \nu$ where the averaging is over the polarization. ${ }^{27}$ We obtained $\tau_{\text {rad }}=330 \mu \mathrm{s}$. The fluorescence lifetime was measured using powder obtained from single crystals of $\mathrm{Yb}$ :LiGdMo, diluted in ethylene glycol. The result was $\tau_{f}=250 \mu \mathrm{s}$. Both values can be compared with those similarly obtained for LiYbMo $\left(\tau_{\text {rad }}=235 \mu\right.$ s and $\tau_{f}$ $=183 \mu \mathrm{s})$ using slightly updated results in comparison with Ref. 20.

The maximum absorption cross sections near $975 \mathrm{~nm}$ (suitable for diode pumping) amount to 1.64 and 1.17 $\times 10^{-20} \mathrm{~cm}^{2}$ for the $\pi$ and $\sigma$ polarizations, respectively. The absorption peak near $933 \mathrm{~nm}$, however, is also very high for the $\sigma$ polarization $\left(1.15 \times 10^{-20} \mathrm{~cm}^{2}\right)$. The maximum emission cross section is obtained for the $\pi$ polarization near $1000 \mathrm{~nm}: 3.3 \times 10^{-20} \mathrm{~cm}^{2}$.

\section{LASER EXPERIMENTS}

The initial laser experiments with Ti:sapphire and tapered diode laser pumping were conducted at room temperature using an uncoated $2.6 \mathrm{~mm}$ thick plate sliced from the $\mathrm{LiGd}_{0.936} \mathrm{Yb}_{0.064} \mathrm{Mo}$ boule. The relatively large sample (see Fig. 1) was in contact with the copper holder only at two edges of one of the surfaces and was practically uncooled. It had a $c$ axis approximately $45^{\circ}$ out of the surface plane and was inserted under Brewster angle in the three-mirror astigmatically compensated laser cavity, shown in Fig. 5(a). The $74 \mathrm{~cm}$ long cavity consisted of an end mirror $M_{1}$ with a radius of curvature of $-5 \mathrm{~cm}$; a folding mirror $M_{2}$ with a radius of curvature of $-10 \mathrm{~cm}$, through which the pump beam was focused by a $f$ $=6.28 \mathrm{~cm}$ lens $L$; and a plane output coupler $M_{3}$ of transmission $T_{\mathrm{OC}}$. Pumping was realized only in a single pass since mirror $M_{1}$ was also highly transmitting at the pump wavelength. The pump beam was polarized always in the plane of Fig. 5(a) and the Brewster geometry forced the $\mathrm{Yb}$ laser to oscillate also in the same plane. This plane also contained the normal to the polished surfaces and the $\boldsymbol{c}$ axis. Under these conditions the two nonequivalent possibilities for positioning the Yb:LiGdMo sample corresponded to orientation of the electric field vector of the light propagating in it at roughly $20^{\circ}$ and $70^{\circ}$ to the $\boldsymbol{c}$ axis, in which case we designate also as $\pi$ and $\sigma$ polarizations.

Finally, a $50 \mathrm{~W}$ unpolarized fiber-coupled diode laser module was used to study the power limits with diode pumping with the hemispherical cavity shown in Fig. 5(b). In this case an uncoated sample with a thickness of $1.9 \mathrm{~mm}$ and an aperture of $3 \mathrm{~mm} \times 3 \mathrm{~mm}$ was cut from the same plate and mounted in a copper holder with water cooling to maintain the room temperature. The $\boldsymbol{c}$ axis was in the surface plane, which allowed natural selection of the polarization. $M_{1}$ was a plane high reflector for the laser wavelength on a $3 \mathrm{~mm}$ thick quartz substrate that was highly transmitting at the pump wavelength and the concave output coupler had a radius of curvature of $-5 \mathrm{~cm}$. The sample was placed as close as possible ( $\approx 0.2 \mathrm{~mm}$ ) to $M_{1}$.

\section{A. Results under Ti:sapphire laser pumping}

The Ti:sapphire laser pump beam was focused to a spot of $\sim 22 \mu \mathrm{m}$ (Gaussian waist) and the pump power incident onto the $\mathrm{Yb}$ :LiGdMo crystal was limited in this case to $1.8 \mathrm{~W}$. The pump wavelength was $975 \mathrm{~nm}$, corresponding to the maximum of the absorption spectra (Fig. 4). The transmission of the output mirrors used was $T_{\mathrm{OC}}=1.2 \%$, $2.7 \%, 5.5 \%$, and $10 \%$.

Figure 6 shows the change of the crystal absorption measured with increasing incident pump power. Strong absorption bleaching can be seen in the absence of lasing, and laser operation had a recycling effect resulting in recovery of the absorption. This leads to a rather weak dependence of the actual crystal absorption on the incident pump power. The dependence was similar for the two polarizations studied and the absorption was only slightly higher for the $\pi$ polarization. Even for the highest outcoupling used, the intracavity intensity was high enough to substantially compensate the bleaching effect.
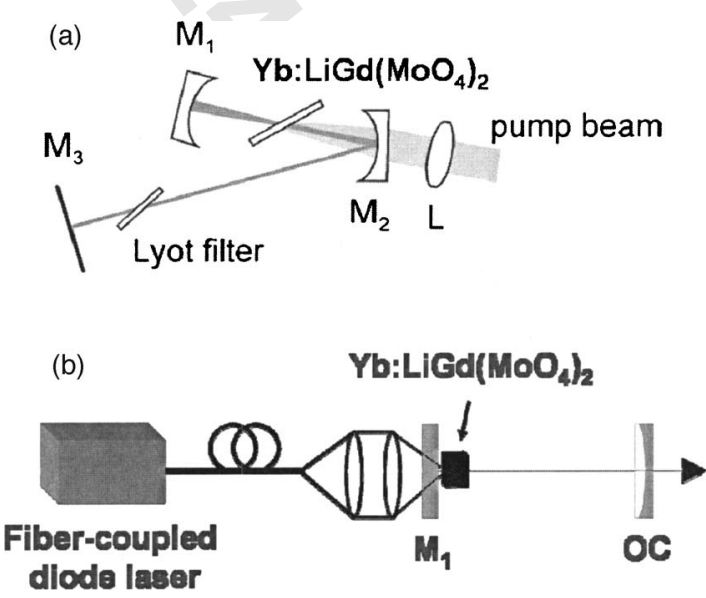

Fig. 5. (a) Schematic of the Yb:LiGdMo laser cavity with the Lyot filter for tuning used with Ti:sapphire and tapered diode lasers as pump sources. (b) Plane-concave cavity without polarization-selecting elements for pumping with the fibercoupled diode module. OC, output coupler. 


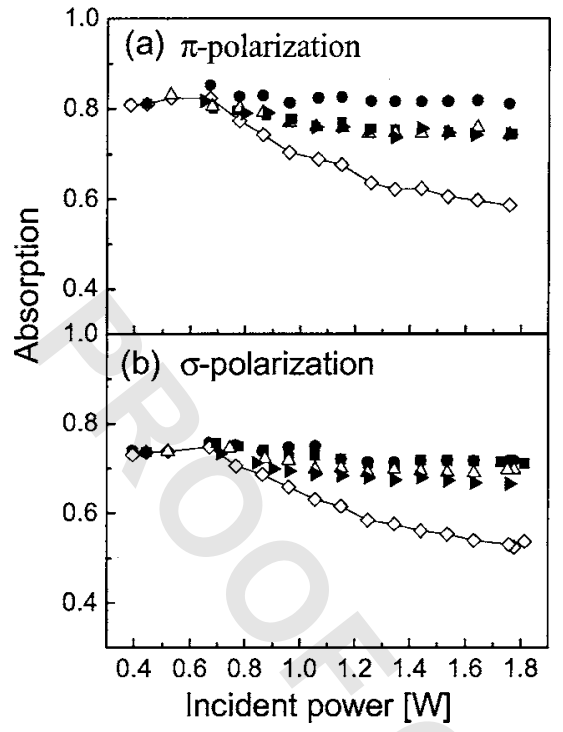

Fig. 6. Single-pass crystal absorption versus incident pump power without lasing (diamonds) and under laser operation for $T_{\mathrm{OC}}=1.2 \%, 2.7 \%, 5.5 \%$, and $10 \%$. (right triangles), (a) $\pi$ polarization and (b) $\sigma$ polarization.

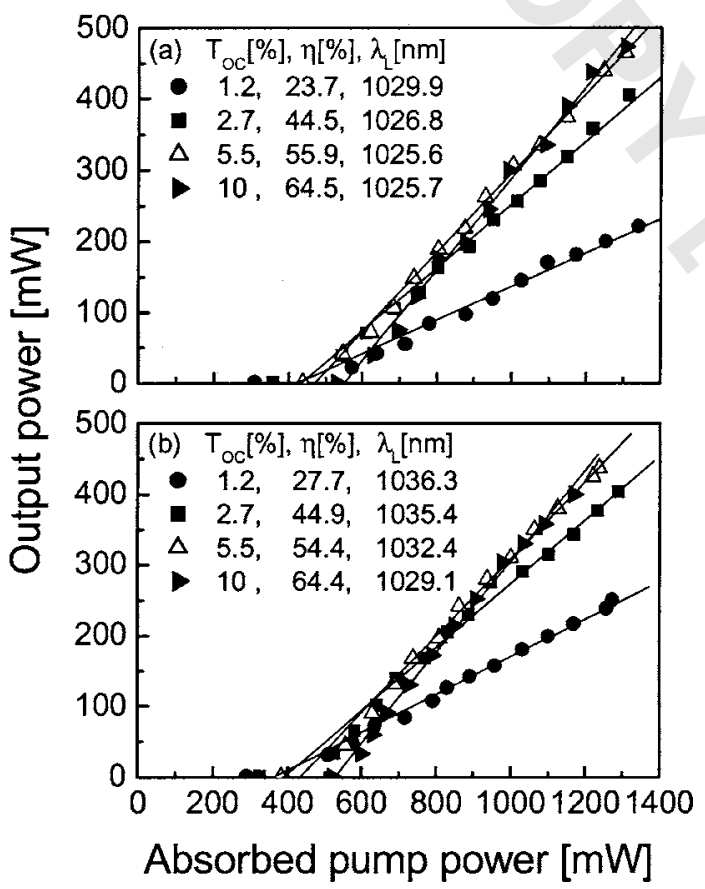

Fig. 7. Output power versus absorbed pump power at $975 \mathrm{~nm}$ for the cw Yb:LiGdMo laser (symbols) for (a) $\pi$ polarization and (b) $\sigma$-polarization. The linear fits shown give the slope efficiencies $\eta$ obtained for the indicated output coupler transmissions $T_{\mathrm{OC}}$.

Figure 7 shows the laser performance (output versus absorbed power) for the two polarization configurations. For $\pi$ polarization [Fig. 7(a)], a maximum output power of $473 \mathrm{~mW}$ was obtained with $T_{\mathrm{OC}}=10 \%$ at a laser wavelength $\lambda_{L}=1025.7 \mathrm{~nm}$. In this case the maximum slope efficiency $(\eta=64.5 \%)$ was also obtained and the absorbed pump power for reaching the laser threshold was $\sim 520 \mathrm{~mW}$. The overall laser performance was quite similar for the two polarizations. The minimum thresholds measured with $T_{\mathrm{OC}}=1.2 \%$ were of the order of $300 \mathrm{~mW}$.
The only substantial difference that could be observed as a trend was that the laser wavelength was always longer for $\sigma$ polarization.

The laser tunability was studied by inserting under Brewster angle a two-plate Lyot filter in the $M_{2}-M_{3}$ cavity arm close to the output coupler (Fig. 5). Under optimum alignment the output power reduction with the filter inside the cavity did not exceed 5\%. Figure 8 shows the tunability achieved with two different output couplers, $T_{\mathrm{OC}}$ $=1.2 \%$ and $5.5 \%$, for an incident pump power of $1.8 \mathrm{~W}$. In both cases these tunability curves were limited on the shortwave side by the spectral characteristics of the cavity mirrors and in particular by the output couplers used. The total tuning range obtained extends from 1016 to $1049 \mathrm{~nm}$. In addition to the longer lasing wavelengths, the tuning curves for $\sigma$ polarization are broader than those for $\pi$ polarization.

The average inversion $\langle\beta\rangle=(1 / d) \int_{0}^{d} \beta(z) \mathrm{d} z$ necessary to achieve the threshold for a sample thickness $d$ and $\mathrm{Yb}$-ion density $N$ can be estimated from $\langle\beta\rangle=\left[2 \sigma_{a} N d-\ln (1\right.$ $\left.\left.-T_{\mathrm{OC}}\right)\right] /\left[2 N d\left(\sigma_{a}+\sigma_{e}\right)\right]$. The computed results for the two polarizations and two different output couplers are plotted in Fig. 9. The comparison with the experimentally observed wavelength dependence is justified because we established that the wavelength changed only slightly from threshold to maximum power (increasing by less that $1 \mathrm{~nm}$ for the $\pi$ and less than $3 \mathrm{~nm}$ for the $\sigma$ polarization for all four output couplers used in Fig. 7). It can be seen from Fig. 9 that for a given output coupling the threshold average inversion has its minimum at longer wavelengths for the $\sigma$ polarization in accordance with the experimental observations in Figs. 7 and 8. Moreover, it can be clearly seen from Fig. 9 that for both polarizations the oscillation wavelength gets shorter with increasing output coupling, a trend experimentally observed not only without a tuning element (Fig. 7) but also evident from the tuning behavior in Fig. 8 .

\section{B. Results under Diode Laser Pumping}

The tapered diode laser (TDL) used for demonstration of diode pumping consisted of a $1 \mathrm{~mm}$ long ridge waveguide

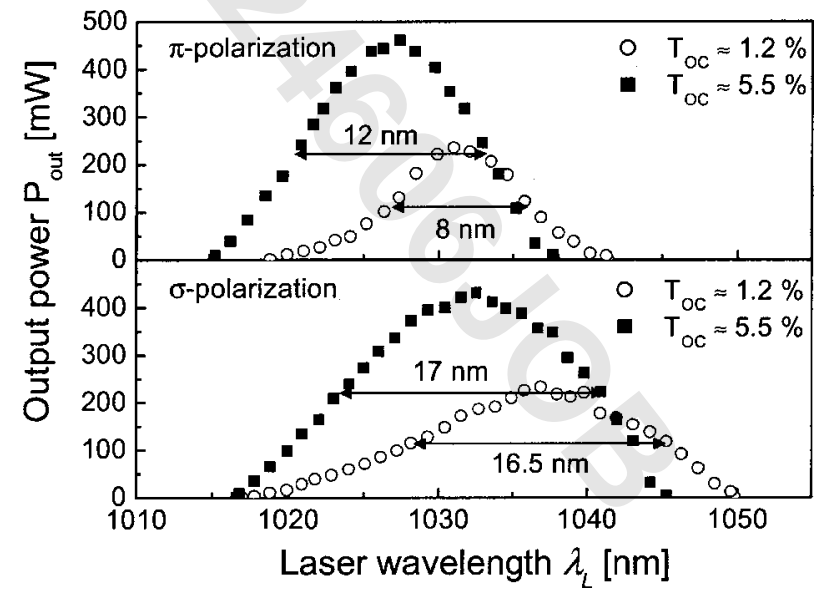

Fig. 8. Wavelength tunability of the Yb:LiGdMo laser under Ti:sapphire laser pumping for an incident pump power $1.8 \mathrm{~W}$ and the two polarizations. Two different output couplers were used: $T_{\mathrm{OC}}=1.2 \%$ and $5.5 \%$ and in both cases the tunability was limited on the shortwave side by the transmission characteristics of the output couplers. 


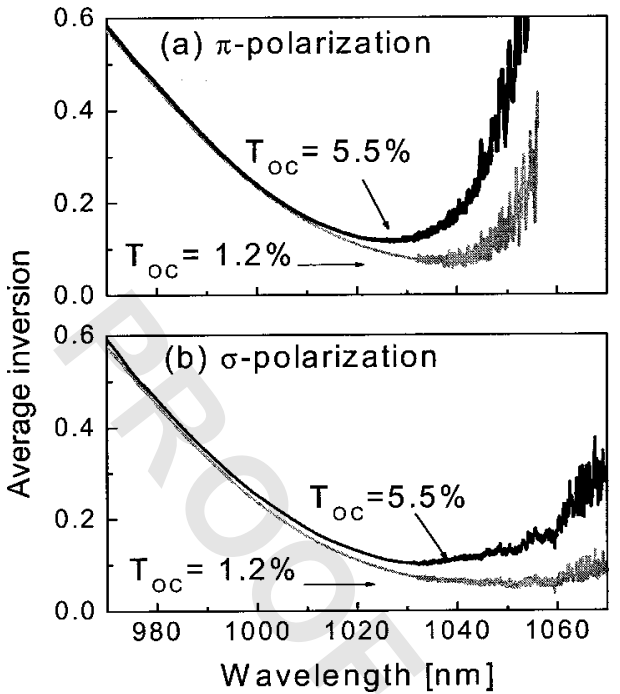

Fig. 9. Calculated average inversion $\langle\beta\rangle$ necessary to achieve threshold versus wavelength for the two polarizations and two different output couplers $\left(T_{\mathrm{OC}}\right)$.
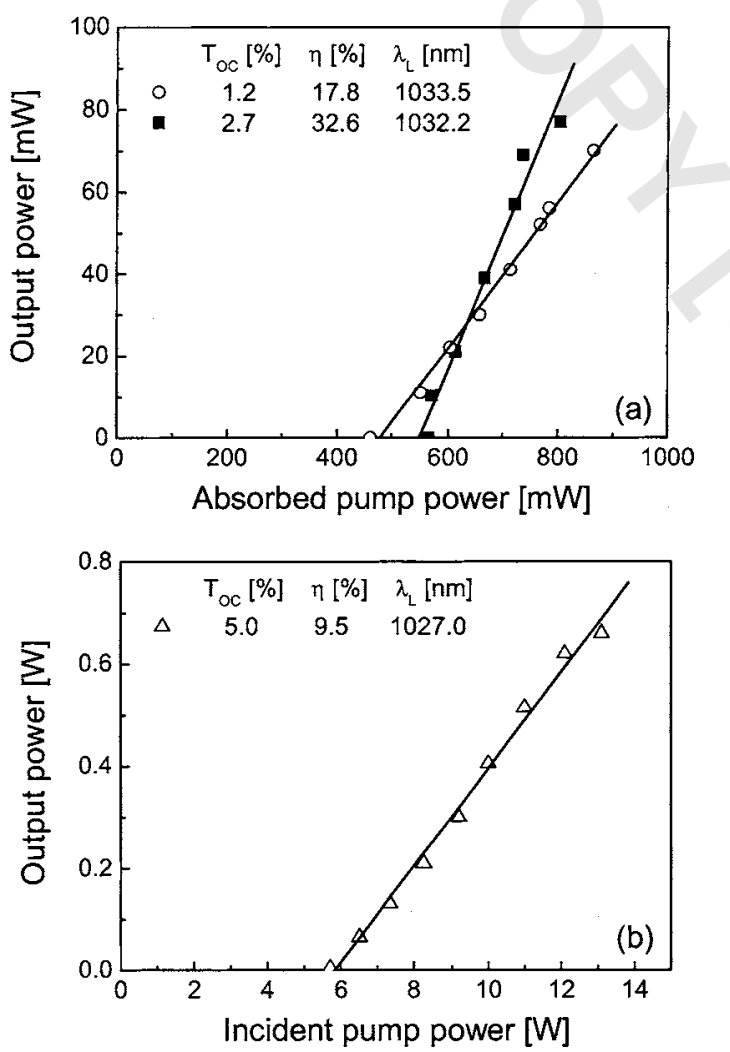

Fig. 10. Output power of the $\pi$-polarized cw Yb:LiGdMo laser pumped (a) by a TDL at $975 \mathrm{~nm}$ and (b) by an unpolarized fibercoupled diode laser module at $980 \mathrm{~nm}$. The lines are the fits used to calculate the slope efficiencies $\eta$ corresponding to the used output couplers $\left(T_{\mathrm{OC}}\right)$.

and a $3 \mathrm{~mm}$ long tapered amplifier section. The highly reflecting ( $>90 \%$ ) facet was $\sim 3 \mu \mathrm{m}$ wide and the output aperture had a width of $300 \mu \mathrm{m}$. The TDL had an output power of up to $1.25 \mathrm{~W}$ at $M^{2}<3$ for the slow axis emission. A collimated pump beam could be formed by relatively simple optics. The spectral linewidth near $975 \mathrm{~nm}$ was $\sim 1 \mathrm{~nm}$. Two output couplers, $T_{\mathrm{OC}}=1.2 \%$ and $2.7 \%$, were used with the same setup depicted in Fig. 5(a). We studied only the $\pi$ polarization.

The absorption bleaching effect was relatively small for the available pump power: The absorption dropped in the absence of lasing from $\sim 85 \%$ to $75 \%$ with increasing pump level. With the output coupler aligned, the recycling effect resulted in some recovery to $\sim 81.5 \%$. An output power of $77 \mathrm{~mW}$ at $1032.2 \mathrm{~nm}$ was obtained for $T_{\mathrm{OC}}$ $=2.7 \%$ [Fig. 10(a)] and the maximum slope efficiency with this output coupler was $\eta=32.6 \%$. For $T_{\mathrm{OC}}=1.2 \%$, the absorbed pump power at the laser threshold was $460 \mathrm{~mW}$.

The $50 \mathrm{~W}$ fiber-coupled diode laser module operated near $980 \mathrm{~nm}$ and had a linewidth of $4 \mathrm{~nm}$. The fiber core diameter was $200 \mu \mathrm{m}$ with a N.A. $=0.22$. The unpolarized pump beam was focused to a spot size of $\sim 100 \mu \mathrm{m}$ using 1:1 imaging optics [Fig. 5(b)]. The best results were obtained with $T_{\mathrm{OC}}=5 \%$ [Fig. 10(b)]. Note that they were affected also by the imperfect parallelism of the uncoated sample. Since the pump beam divergence prevented a precise estimation of the absorbed power, the slope was calculated with respect to the incident pump power and is correspondingly lower. The deviation of the fixed pump wavelength from the absorption maximum (the absorption estimated without lasing was only $\sim 37 \%$ ) and the relatively large pump spot size resulted in an increased threshold $(5.7 \mathrm{~W})$ and low slope efficiency. Nevertheless the maximum output power achieved was $0.66 \mathrm{~W}$. Without any polarization-selective elements, the laser oscillated in the $\pi$ polarization.

\section{CONCLUSION}

We demonstrated, for the first time to our knowledge, laser operation of $\mathrm{Yb}^{3+}$ in a Li-based DM host belonging to the general class of disordered $\mathrm{LiT}\left(\mathrm{XO}_{4}\right)_{2}$ compounds. Efficient and tunable laser operation of $\mathrm{Yb}: \mathrm{LiGd}\left(\mathrm{MoO}_{4}\right)_{2}$ was obtained by pumping it near $975 \mathrm{~nm}$ with a Ti:sapphire laser. In accordance with the gain characteristics that depend on both the emission and the absorption cross sections, longer wavelengths and broader tunability were observed for $\sigma$ polarization. Diode pumping with $\sim 50 \%$ higher threshold was achieved with a TDL and an output power of $0.66 \mathrm{~W}$ was obtained with a fiber-coupled diode laser module. It has been determined that this crystal belongs to the $I \overline{4}$ space group; therefore the presence of two different sites each with multiple environments contributes to the inhomogeneous broadening of the electron transitions that ensures relatively broad laser tunability.

\section{ACKNOWLEDGMENTS}

We thank J. Liu for the measurement and results presented in Fig. 10(b). This work was supported by the projects DT-CRYS or NMP3-CT-2003-505580 (European Union) and MAT 2005-6354-C03-01 and CAM-MAT-4342004 (Spain). M. Rico (EX2003-0784) and X. Han (SB2003-0232) acknowledge the Education and Science Ministry of Spain for financial support. 


\section{REFERENCES}

1. M. Rico, J. Liu, U. Griebner, V. Petrov, M. D. Serrano, F. Esteban-Betegón, C. Cascales, and C. Zaldo, "Tunable laser operation of ytterbium in disordered single crystals of $\mathrm{Yb}: \mathrm{NaGd}\left(\mathrm{WO}_{4}\right)_{2}, "$ Opt. Express 12, 5362-5367 (2004).

2. J. Johannsen, M. Mond, K. Petermann, G. Huber, L. Ackermann, D. Rytz, and C. Dupre, "First $\mathrm{Yb}: \mathrm{NaGd}\left(\mathrm{WO}_{4}\right)_{2}$ solid-state laser pumped by Ti:sapphire and diode laser," in Advanced Solid-State Photonics Vol. 98 of OSA Trends in Optics and Photonics Series (Optical Society of America, 2005), paper MB44.

3. J. Johannsen, M. Mond, K. Petermann, G. Huber, L. Ackermann, D. Rytz, C. Dupre, M. D. Serrano, F. EstebanBetegón, C. Cascales, C. Zaldo, M. Rico, J. Liu, U. Griebner, and V. Petrov, "Yb: $\mathrm{NaGd}\left(\mathrm{WO}_{4}\right)_{2}$ tunable solidstate laser operation with Ti:sapphire and diode laser pumping" in Conference on Lasers and Electro-Optics (CLEO) OSA Trends in Optics and Photonics Series (Optical Society of America, 2005), paper CMS2.

4. J. Liu, J. M. Cano-Torres, C. Cascales, F. Esteban-Betegón, M. D. Serrano, V. Volkov, C. Zaldo, M. Rico, U. Griebner, and V. Petrov, "Growth and continuous-wave laser operation of disordered crystals of $\mathrm{Yb}^{3+}: \mathrm{NaLa}\left(\mathrm{WO}_{4}\right)_{2}$ and $\mathrm{Yb}^{3+}: \mathrm{NaLa}\left(\mathrm{MoO}_{4}\right)_{2}$," Phys. Status Solidi A 202, R29-R31 (2005).

APC:

5. J. Liu, J. M. Cano-Torres, F. Esteban-Betegón, M. D. Serrano, C. Cascales, C. Zaldo, M. Rico, U. Griebner, and V. Petrov, "Continuous-wave diode-pumped operation of an $\mathrm{Yb}: \mathrm{NaLa}\left(\mathrm{WO}_{4}\right)_{2}$ laser at room temperature," Opt. Laser Technol. (2006), in press.

6. A. V. Mandrik, A. E. Troshin, V. E. Kisel, A. S. Yasukevich, G. N. Klavsut, N. V. Kuleshov, and A. A. Pavlyuk, "CW and Q-switched diode-pumped laser operation of $\mathrm{Yb}^{3+}: \mathrm{NaLa}\left(\mathrm{MoO}_{4}\right)_{2}$," Appl. Phys. B 81 1119-1121 (2005).

7. M. Rico, J. Liu, J. M. Cano-Torres, A. Garcia-Cortés, C. Cascales, C. Zaldo, U. Griebner, and V. Petrov, "Continuous wave and tunable laser operation of $\mathrm{Yb}^{3+}$ in disordered $\mathrm{NaLa}\left(\mathrm{MoO}_{4}\right)_{2}$," Appl. Phys. B 81, 621-625 (2005).

8. S. Rivier, M. Rico, U. Griebner, V. Petrov, M. D. Serrano, F. Esteban-Betegón, C. Cascales, C. Zaldo, M. Zorn, and M. Weyers, "Sub-80 fs pulses from a mode-locked $\mathrm{Yb}: \mathrm{NaGd}\left(\mathrm{WO}_{4}\right)_{2}$ laser," in Conference on Lasers and Electro-Optics (CLEO), OSA Trends in Optics and Photonics Series (Optical Society of America, 2005), paper CF4-4-THU.

9. P. V. Klevtsov, L. P. Kozeeva, and L. Yu. Kharchenko, "Study on the crystallization and polymorphism of double potassium and trivalent metal tungstates, $\mathrm{KR}\left(\mathrm{WO}_{4}\right)_{2}$," Sov. Phys. Crystallogr. 20, 732-735 (1975); [Kristallografiya 20, 1210-1215 (1975)].

10. A. A. Kaminskii, A. A. Mayer, S. E. Sarkisov, and M. V. Provotorov, "Investigation of stimulated emission from $\mathrm{LiLa}\left(\mathrm{MoO}_{4}\right)_{2}: \mathrm{Nd}^{3+}$ crystal laser," Phys. Status Solidi A 17, K115-K117 (1973).

11. A. A. Kaminiskii and S. E. Sarkisov, "Investigation of the stimulated emission due to ${ }^{4} F_{3 / 2} \rightarrow{ }^{4} I_{13 / 2}$ transition in $\mathrm{Nd}^{3+}$ ions in crystals. IV," Sov. J. Quantum Electron. 3, 248-249 (1974); , [Kvant. Elektron. (Moscow) 15, 106-108 (1973)].

12. V. A. Mikhailov, A. I. Zagumennyi, Yu. D. Zavartsev, V. A Kondratyuk, P. A. Studenikin, I. A. Shcherbakov, Y. Jang, S. Chae, and I. Bae, "Diode pumped $\mathrm{LiLa}_{1-\mathrm{x}} \mathrm{Nd}_{\mathrm{x}}\left(\mathrm{MoO}_{4}\right)_{2}$ and $\mathrm{Nd}: \mathrm{Bi}_{4} \mathrm{Ge}_{3} \mathrm{O}_{12}$ lasers," in Postconference Digest, Vol. 39 of OSA Trends in Optics and Photonics (Optical Society of America, 2000), Conference on Lasers and Electro-Optics (CLEO), paper CTuK54, p. 113.

13. A. A. Kaminskii, A. A. Mayer, N. S. Nikonova, M. V. Provotorov, and S. E. Sarkisov, "Stimulated emission from the new $\mathrm{LiGd}\left(\mathrm{MoO}_{4}\right)_{2}: \mathrm{Nd}^{3+}$ crystal laser," Phys. Status Solidi A 12, K73-K75 (1972).

14. A. A. Kaminskii, P. V. Klevtsov, Kh. S. Bagdasarov, A. A. Maier, A. A. Pavlyuk, A. G. Petrosyan, and M. V. Provotorv, "New cw crystal lasers," JETP Lett. 16, 387-389 (1972); [Zh. Eksp. Teor. Fiz. Pis'ma Red. 16, 548-551 (1972)].

15. P. V. Klevtsov and L. P. Kozeeva, "Synthesis of double lithium molybdates of rare earths and yttrium," Inorg. Mater. 5, 1571-1572 (1969); [Izv. Akad. Nauk SSSR Neorg. Mater. 5, 1842-1843 (1969)].

16. M. V. Mokhosoev, E. I. Get'man, and F. P. Alekseev, "Double molybdates of the alkali and rare-earth elements with the composition $\mathrm{MeLn}\left(\mathrm{MoO}_{4}\right)_{2}$," Dokl. Chem. 185, 201-202 (1969); [Dokl. Akad. Nauk SSSR 185, 361-362 (1969)].

17. A. N. Egorova, A. A. Maier, N. N. Nevskii, and M. V. Provotorov, "The crystal-structure of $\mathrm{LiCe}\left(\mathrm{MoO}_{4}\right)_{2}$," Inorg. Mater. 18, 1763-1766 (1982); [Izv. Akad. Nauk SSSR Neorg. Mater. 18, 2036-2038 (1982)].

18. U. Kolitsch, "The crystal structures of phenacite-type $\mathrm{Li}_{2}\left(\mathrm{MoO}_{4}\right)$, and scheelite-type $\mathrm{LiY}\left(\mathrm{MoO}_{4}\right)_{2}$ and $\mathrm{LiNd}\left(\mathrm{MoO}_{4}\right)_{2}$," Z. Kristallogr. 216, 449-454 (2001).

19. R. F. Klevtsova, "The crystal structure of lithium lanthanum molybdate $\alpha$ - $\operatorname{LiLa}\left(\mathrm{MoO}_{4}\right)_{2}, "$ Sov. Phys. Crystallogr. 20, 456-458 (1975); [Kristallografiya 20, 746-750 (1975)].

20. V. Volkov, C. Cascales, A. Kling, and C. Zaldo, "Growth, structure, and evaluation of laser properties of $\mathrm{LiYb}\left(\mathrm{MoO}_{4}\right)_{2}$ single crystal," Chem. Mater. 17, 291-300 (2005).

21. W. H. McCaroll and M. Greenblatt, "Preparation of lithium molybdenum oxide bronzes by a temperature gradient flux growth technique,” J. Solid State Chem. 54, 282-290 (1984).

22. B. Sh. Galyamov, Yu. E. Roginskaya, M. V. Provotorov, S. A. Okonenko, and Yu. N. Venevtsev, "Defect structure and phase transitions in $\mathrm{LiR}\left(\mathrm{MoO}_{4}\right)_{2}$ compounds $(\mathrm{R}=\mathrm{Nd}, \mathrm{Gd})$," Sov. Phys. Solid State 20, 1103-1105 (1978); [Fiz. Tverd. Tela 20, 1907-1910 (1978)].

23. P. Porcher, M. Couto dos Santos, and O. Malta, "Relationship between phenomenological crystal field parameters and crystal structure. The simple overlap model," Phys. Chem. Chem. Phys. 1, 397-405 (1999).

24. M. Rico, "Espectroscopia óptica del $\mathrm{Er}^{3+}$ y su sensibilización con $\mathrm{Yb}^{3+}$ en monocristales conversores de frecuencia," Ph.D. dissertation (Universidad Autónoma de Madrid, 2003).

25. P. Porcher, "Fortran routines REEL and IMAGE for APC: simulation of $d^{\mathrm{N}}$ and $\mathrm{f}^{\mathrm{N}}$ configurations involving real and \#6 complex crystal-field parameters" (1989), unpublished.

26. D. E. McCumber, "Einstein relations connecting broadband emission and absorption spectra," Phys. Rev. 136, A954-A957 (1964).

27. M. C. Pujol, M. A. Bursukova, F. Güell, X. Mateos, R. Solé, Jna. Gavaldá, M. Aguiló, J. Massons, F. Díaz, P. Klopp, U. Griebner, and V. Petrov, "Growth, optical characterization, and laser operation of a stoichiometric crystal $\mathrm{KYb}\left(\mathrm{WO}_{4}\right)_{2}$," Phys. Rev. B 65, 165121 (2002). 